\title{
Indications of hysteresis and early warning signals of reduced community resilience during a Bering Sea cold anomaly
}

\author{
Michael A. Litzow* \\ Farallon Institute for Advanced Ecosystem Research, 101 H St., Suite Q, Petaluma, CA 95952, USA
}

\begin{abstract}
The presence of early warning signals (EWS) for regime shifts was tested for in the Bering Sea demersal community during a 2006 to 2013 cold anomaly. During this cold period, community-wide recruitment and distribution patterns failed to reverse responses observed during the previous 2 to 4 decades of warming. These observations are consistent with a model of alternative states - a cold community state and warm community state - separated by hysteresis in the response to temperature. This model predicts that declining resilience of the warm community state during the cold anomaly should have been accompanied by elevated EWS as the system experienced critical slowing down in recovery from stochastic perturbations. This prediction was tested with time series for 3 EWS (temporal autocorrelation, spatial variability, spatial autocorrelation) calculated from distribution data for 12 common fishes and crabs from the Bering Sea trawl survey (1982 to $2015, \mathrm{n}=285$ sets $\mathrm{yr}^{-1}$ ), for a total of 36 taxon $\times$ EWS combinations. Fifteen of the 36 time series were significantly elevated during the cold anomaly (community-wide randomization test, $\mathrm{p}<0.0001$ ). Comparison with a 'control' group of 3 cold years outside of the cold anomaly failed to replicate observations of elevated EWS, suggesting that the EWS signal was due to the persistent perturbation of the cold anomaly rather than temperature effects on the distribution and behavior of study animals per se. These results suggest that theoretical predictions for EWS may be supported in large ecosystems such as the Bering Sea.
\end{abstract}

KEY WORDS: Early warning signals - Ecosystem based fisheries management $\cdot$ Regime shift · Climate $\cdot$ Critical slowing down $\cdot$ Hysteresis $\cdot$ Resilience $\cdot$ Bering Sea

\section{INTRODUCTION}

Biological communities occasionally undergo abrupt 'regime shifts' between persistent contrasting states (Isaacs 1975, Möllman et al. 2015). As the pace of anthropogenic perturbation to ecosystems increases globally, there is an expectation that regime shifts will become more common (Möllman et al. 2015). Accordingly, there is great interest in developing approaches that will give early warning of impending regime shifts, either to allow managers to attempt to prevent the shift, or at least to provide the opportunity to prepare for sudden disruption to coupled ecological-economic systems.

\footnotetext{
*Corresponding author: litzow@faralloninstitute.org
}

Recently, the idea that systems approaching a regime shift might present characteristic statistical behaviors that could serve as early warning signals (EWS) of the shift has been advanced in the ecological literature. This idea has been successfully demonstrated with a variety of simple ecological models (Scheffer et al. 2009, Kéfi et al. 2013), by experimental manipulations to laboratory microcosms (Drake \& Griffen 2010, Dai et al. 2012), and in simple, small, closed ecosystems (Carpenter et al. 2011, Veraart et al. 2012, Wang et al. 2012). This research suggests the possibility that EWS might ultimately be useful in the large, complex, open ecosystems that are of most interest to managers. While the concept of ecosys-

() The author 2017. Open Access under Creative Commons by Attribution Licence. Use, distribution and reproduction are unrestricted. Authors and original publication must be credited. 
tem-based fisheries management (EBFM) has been around for decades, ecologists have struggled to find a way to condense the vast amount of information that might be monitored in an ecosystem into a quantitative summary of ecosystem state that would convey useful information to managers (Essington \& Punt 2011). With their promise of a simple approach for quantifying the relative likelihood that a system might undergo a regime shift, EWS seem to present exactly the sort of tool that is needed in this context.

However, attempts to apply EWS to large, complex systems have produced mixed results (Litzow \& Hunsicker 2016). A number of potential problems may complicate the application of EWS in 'real world' management situations. A particular problem is that the true model of dynamics underlying a regime shift is never known in large, complex systems (Möllman et al. 2015). There are many classes of theoretical regime shift models, some of which produce EWS, others of which do not (Hastings \& Wysham 2010, Kéfi et al. 2013, Dakos et al. 2015). If empirical ecologists are unsure which, if any, of these models applies to their system, little guidance is available on whether EWS should be present or not.

Empirical work on EWS might therefore benefit from attempts to determine if the study system is governed by a model showing EWS dynamics. The most obvious choice would be the 'saddle node' or 'fold bifurcation' model of alternative stable states, which has been the focus of most theoretical EWS research (Carpenter \& Brock 2006, Scheffer et al. 2009, Boettiger \& Hastings 2012b, Dakos et al. 2015). Under this model, a system experiences critical slowing down as it approaches a tipping point into an alternative state. Critical slowing down occurs because as the system approaches the tipping point (ecological resilience declines), the basin of attraction shoals (engineering resilience declines). Stochastic perturbations are then more able to dislodge the system from its mean condition, and recovery to the mean becomes slower (Scheffer et al. 2009, Boettiger \& Hastings 2012b, Dakos et al. 2015). The most commonly proposed EWS are statistical signals of critical slowing down, such as increased spatial-temporal variability and autocorrelation in key system parameters (Scheffer et al. 2012).

Systems governed by alternative stable state dynamics are therefore logical choices for empirical research on EWS. However, demonstrating the presence of alternative stable states in large, open ecosystems is extremely difficult (Petraitis \& Dudgeon 2004, Schröder et al. 2005, Dudgeon et al. 2010). Because conclusive tests for alternative stable states in these systems are typically impossible, ecologists interested in alternative stable state dynamics have tested for key observations that provide hints that these dynamics may be at work. One of these key observations is hysteresis, or reaction to an external forcing parameter that differs for different directions of change in external conditions, due to positive feedbacks in the system or a difference in the set of variables controlling the biological response in different states (Scheffer \& Carpenter 2003, Bestelmeyer et al. 2011, Wang et al. 2012). While conclusive demonstration of hysteresis with observational data is extremely challenging, tests for state-dependent behavior in driver-response relationships are statistically straightforward, and allow empiricists to test for dynamics that are consistent with hysteresis. Specifically, the expectation for hysteresis is that the biological response depends on the direction of change in the external parameter (Beisner et al. 2003, Samhouri et al. 2010, Hunsicker et al. 2016). This test provides necessary but not sufficient evidence for the presence of hysteresis and alternative states (Beisner et al. 2003, Petraitis \& Dudgeon 2016). This approach offers an attractive compromise between the need to demonstrate the suitability of a given system for EWS research, and the difficulties of testing for nonlinear dynamics in empirical systems (Litzow \& Hunsicker 2016).

Recently, the eastern Bering Sea, a highly productive ecosystem that supports extremely valuable fisheries, has exhibited possible hysteresis in community responses to climate variability. During most of the 20th century, fish and crustacean communities in the Bering Sea and neighboring Gulf of Alaska were tightly coupled with temperature. Climate shifts associated with the Pacific Decadal Oscillation in the 1940s (warm to cold) and 1976/1977 (cold to warm) were associated with abrupt community-wide changes in population trajectories. The 1976/1977 event was particularly well studied. This climate shift resulted in a sudden $\sim 1^{\circ} \mathrm{C}$ increase in average winter sea surface temperatures (SST) in the Bering Sea and Gulf of Alaska, which was associated with rapid increases in the abundance of salmon Oncorhynchus spp., and most groundfishes (e.g. cod Gadus macrocephalus, rock sole Lepidopsetta spp.), and rapid declines in abundance of cold-water groundfishes (e.g. Greenland turbot Reinhardtius hippoglossoides) and crustaceans (shrimp, crabs; Mantua et al. 1997, Anderson \& Piatt 1999, Benson \& Trites 2002, Conners et al. 2002, Litzow 2006). Overfishing also contributed to the collapse of crustacean stocks (Orensanz et al. 1998). Changes in recruitment (for groundfish) or early marine survival (for salmon) are thought to be 
key mechanisms causing shifts in community dominance following the 1976/1977 temperature shift (Hollowed et al. 2001, Mueter et al. 2002, Wilderbuer et al. 2002). In addition to these changes in recruitment and community composition following sudden climate shifts in the Bering Sea, community-wide responses have also been noted during more gradual warming since the early 1980s. In particular, warming temperatures are associated with northward range shifts for most fishes and crustaceans (Mueter \& Litzow 2008, Kotwicki \& Lauth 2013). Thus, the Bering Sea community has responded to both abrupt and gradual warming. However, between 2006 and 2013, the Bering Sea experienced anomalous cold, with temperatures falling to levels similar to those last seen during the cold regime of the 1940s to 1970s. During this cold anomaly, the Bering Sea community apparently failed to reverse earlier biological responses to warming. Fisheries catches remained consistent with the high-salmon, high-groundfish, low-crustacean warm community state. And the fish and crustacean community largely failed to reverse previous northward distribution shifts (Kotwicki \& Lauth 2013). These observations suggest the possibility of hysteresis in community-temperature relationships, with responses to cooling and warming taking different trajectories over an overlapping range of temperatures (Beisner et al. 2003).

The goals of this study were to (1) formally test for hysteresis that would be consistent with a model of alternative states in the response of the Bering Sea fish and crustacean community to temperature variability; and (2) test for elevated EWS consistent with critical slowing down and declining resilience during the persistent perturbation of the cold anomaly. The prediction of elevated EWS is framed in terms of hysteresis and possible alternative states in the community (Box 1). Finally, EWS patterns during the cold anomaly were compared with other cold years to test for false positive EWS (e.g. more variable distribution that is inherent in cold years, regardless of community resilience). This analysis showed that community-wide EWS were strongly elevated during the perturbation of the cold anomaly, in agreement with theoretical predictions.

\section{METHODS}

\section{Study design}

This study attempted to answer 2 questions: (1) is there evidence consistent with hysteresis in the biological response to temperature variability during the cooling period, and (2) if so, did the community show EWS consistent with critical slowing down and declining resilience during the period of hysteresis? Most empirical tests of EWS have relied on observations prior to abrupt shifts that are believed to be consistent with catastrophic ecosystem transitions (Litzow \& Hunsicker 2016). However, these events are by their nature rare, and few such instances are available for studying EWS behavior. In this study, a complementary approach was taken. Rather than testing for elevated EWS prior to an abrupt transition, a situation indicating the likelihood of declining resilience (i.e. delayed biological response to persistent perturbation) was examined to test the theoretical prediction that this decline in resilience should be accompanied by elevated EWS.

For the first study question, biological observations that are available on 2 time scales were used. Recruitment or production estimates for groundfish, crabs, and salmon are available for the period between 1960 and 2013. North-south patterns of community distribution are available from the Bering Sea trawl survey between 1982 and 2015. The relevant question in testing for hysteresis is whether the trajectory of the response to cooling retraces the trajectory for warming (Beisner et al. 2003), so both biology time series were examined for responses to temperature that differed between periods of warming and cooling trends. The peak observed winter SST during the study occurred in 2002/2003 with a predominantly increasing temperature trend before this time, and a decreasing trend afterwards (see 'Data', below). Accordingly, this warmest point was used to distinguish a period when the Bering Sea was generally warming (1960 to 2002) from a period when it was generally cooling (2003 to 2013). In 2014/2015, warm temperatures again reasserted themselves. Previous studies in Alaska have shown that the processes underlying the biological parameters used in this study (i.e. distribution, recruitment, early marine survival) respond to changing temperature at lags of 0 to 1 yr (Litzow 2006, Mueter \& Litzow 2008, Litzow et al. 2014), which makes the post-2002/2003 cooling period adequately long to test for expected effects.

For the second question, EWS were calculated with distribution data from the trawl survey. Because EWS time series were noisy and short, a $t$-test approach was used rather than a test for trends. Specifically, the prediction of elevated EWS during a persistent perturbation (Box 1) was tested, not by a trend test across the entire cooling period, but rather by comparison of EWS from the cold anomaly years (2006 to 2013) with other years in the time series (1982 to 2005, 2014/2015). 
Box 1. Bering Sea community response to temperature: observations in the context of alternate stable state theory and early warning signals (EWS). (a) Community state is tested for response to temperature variability that differs between warming period and cooling period (solid arrows). If observed, biological responses that depend on the direction of temperature change are consistent with hysteresis and bistability, where the warm and cold community states can each exist over the same range of temperature. $F_{1}$ and $F_{2}$ are critical points denoting hypothesized fold bifurcations between the 2 states. Directly demonstrating the presence of fold bifurcations in observational datasets is extremely difficult (Petraitis \& Dudgeon 2004, Schröder et al. 2005, Dudgeon et al. 2010). However, if the effects of temperature depend on the direction of temperature change, the system is in one important sense consistent with alternate stable state theory, which then predicts that a prolonged perturbation (i.e. the 2006 to 2013 cold anomaly) should reduce resilience in the warm community state and make the system more vulnerable to reversion back to the cold community state. This decline in resilience includes both ecological resilience (the system moves closer to a bifurcation point) and engineering resilience (the system loses the ability to resist perturbation). Changes in engineering resilience are depicted by ball and cup diagrams of alternate basins of attraction (the cold community state and warm community state), both (b) close to and (c) far from $F_{2}$. In (b), the slope of the basin of attraction (dashed arrow, equal to engineering resilience, $R_{E}$ ) is shallow. Stochastic perturbations move the system farther from the center of the basin of attraction, creating increased variability (horizontal arrow). The shallow slope of $R_{E}$ results in slow recovery from perturbations. The opposite set of conditions occurs in (c). As a result of these differences, variability (SD) and autocorrelation are higher when the system is (d) close to a tipping point, and lower when it is (e) far from a tipping point

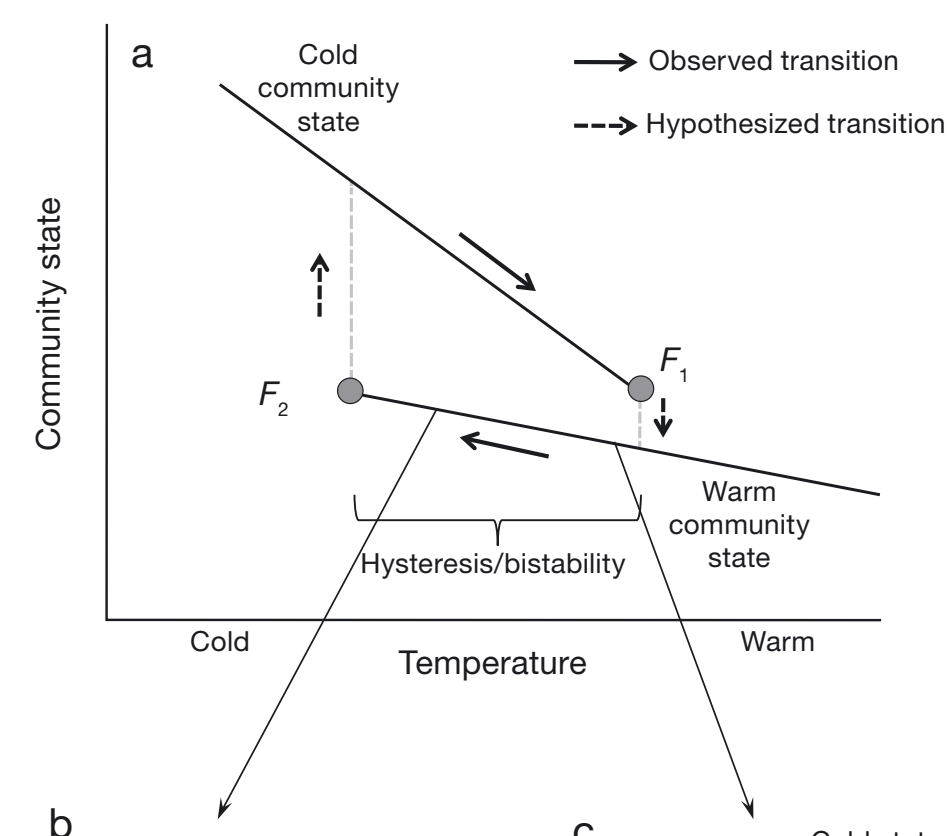

Warm state

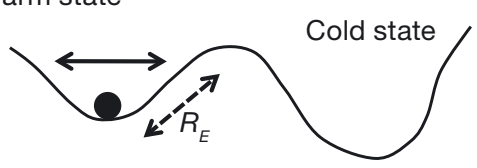

C

Cold state
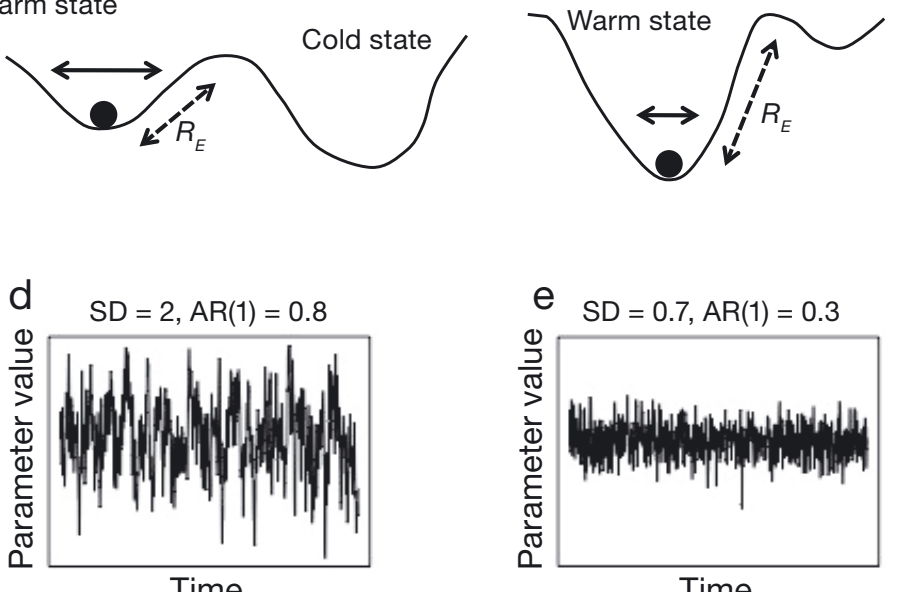

Time

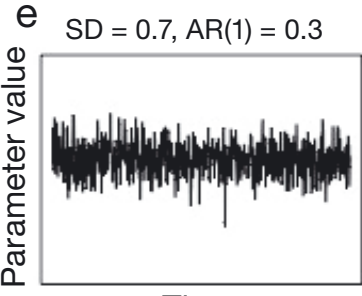

Time

\section{Data}

Groundfish and crab recruitment estimates from age-structured assessment models, lagged to cohort year (age-0) were obtained from the North Pacific Fisheries Management Council (The Plan Team for the Groundfish Fisheries of the Bering Sea and Aleutian Islands 2015, The Plan Team for the King and Tanner Crab Fisheries of the Bering Sea and Aleutian Islands 2016). Model recruitment estimates at the ends of time series are often not supported by empirical information on cohort strength and tend to be unreliable for this reason. These uncertain estimates were identified by examining confidence intervals for model output or from caveats included in assessment reports, and these years were excluded from analysis. Salmon production data (commercial catch lagged to year of ocean entry) were obtained from the Alaska Department of Fish and Game (www.adfg.alaska. gov). Salmon fisheries in the Bering Sea have been fully developed for many decades, such that catches are considered a good proxy for interannual variability in production (Hare et al. 1999, Hare \& Mantua 2000). The relationship between catches and production is supported by analysis of early marine survival using spawner-recruit time series, which show responses to temperature variability that are similar to those observed for catches (Mueter et al. 2002, 2005). However, catch data are available at longer time scales than spawner-recruit data, and provide more 
thorough spatial coverage, and are therefore superior for the purposes of this study.

In order to capture the biological response to the last cold-to-warm transition, only time series of recruitment and production with at least $5 \mathrm{yr}$ of data available from the pre-1976/1977 cold period in the Bering Sea were included. The resulting group of species included walleye pollock Gadus chalcogrammus, Greenland turbot Reinhardtius hippoglossoides, Chinook salmon Oncorhynchus tshawytscha, sockeye salmon $O$. kisutch, coho salmon O. gorbuscha, chum salmon O. keta, and Tanner crab Chionoecetes bairdi. This group include both warm-affiliated species (walleye pollock, salmon) and cold-affiliated species (Greenland turbot, Tanner crab), based on past temperature-abundance and temperature-recruitment correlations (Hare \& Mantua 2000, Zheng \& Kruse 2006, Litzow \& Urban 2009).

Biological data also included catch per unit effort (CPUE; kg ha ${ }^{-1}$ swept) from bottom trawl surveys conducted annually by the US National Marine Fisheries Service during 1982 to 2015. Sampling occurs on a 20 nautical mile $(37 \mathrm{~km})$ grid over a period of 8 wk between May and August. Stauffer (2004) described the trawl survey gear and methods, and Lauth \& Nichol (2013) provided details on sampling design and survey data analysis. To ensure data comparability across years, this analysis was restricted to stations that were sampled in every year of the time series $(\mathrm{n}=285$; Fig. 1). Species caught in this survey that were included in the analyses are listed in Table 1.
Climate data included Bering Sea winter SST (November to March) extracted from the extended reconstructed sea surface temperature (ERSST) v3b dataset (Smith et al. 2008; www.ncdc.noaa.gov), and summer bottom temperature as measured on the trawl survey. Winter SST values were used because this is the season of more coherent low-frequency variability in North Pacific SST (Yeh et al. 2011), and because winter SST is tightly coupled with winter ice extent, which creates a cold pool of bottom water that is protected from summer mixing by the thermocline, such that winter surface temperature largely drives variability in summer conditions for demersal taxa (Wyllie-Echeverria \& Wooster 1998, Stabeno et al.

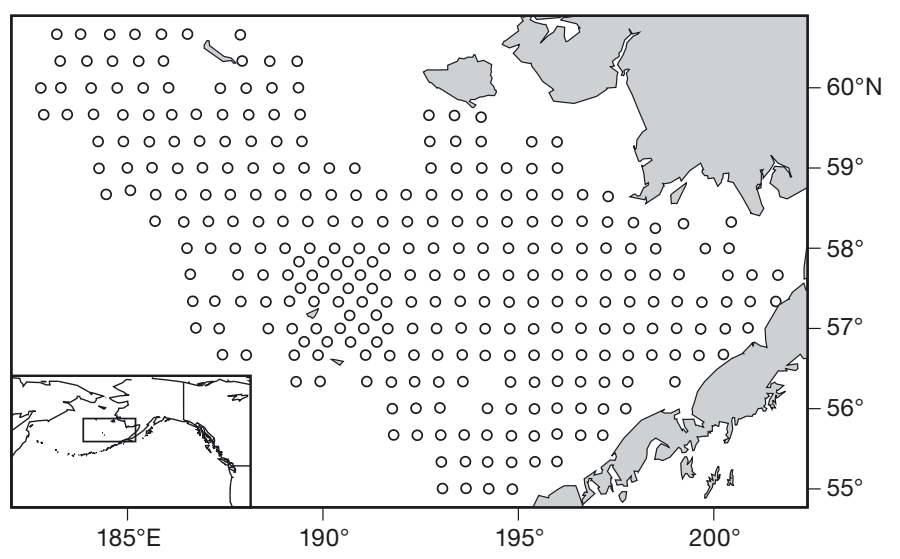

Fig. 1. Trawl survey stations sampled every year between 1982 and 2015. Inset shows study area location in the Bering Sea

Table 1. Taxa used in tests for elevated early warning signals (EWS) during the 2006 to 2013 cold anomaly. Monte Carlo results are p-values for 1-tailed tests for elevated values of each EWS during the cold anomaly compared with the rest of the 1982 to 2015 time series. AR(1): first-order temporal autocorrelation; SDL: standard deviation of log-transformed catch per unit effort; $\mathrm{p}$-values $\leq 0.05$ in bold

\begin{tabular}{|c|c|c|c|c|c|}
\hline \multirow[t]{2}{*}{ Common name } & \multirow[t]{2}{*}{ Scientific name } & \multirow{2}{*}{$\begin{array}{l}\mathrm{n} \text { (mean number } \\
\text { of stations present) }\end{array}$} & \multicolumn{3}{|c|}{ Monte Carlo results } \\
\hline & & & $\mathrm{AR}(1)$ & SDL & Moran's $I$ \\
\hline Arrowtooth flounder & Atheresthes spp. & 152 & 0.3899 & 0.1516 & 0.5416 \\
\hline Tanner crab & Chionoecetes bairdi & 201 & 0.0486 & 0.3031 & 0.0599 \\
\hline Snow crab & Chionoecetes opilio & 208 & 0.0883 & 0.4999 & 0.1563 \\
\hline Walleye pollock & Gadus chalcogrammus & 276 & 0.0140 & 0.0001 & 0.0266 \\
\hline Pacific cod & Gadus macrocephalus & 275 & 0.0636 & 0.0568 & 0.1094 \\
\hline Flathead sole & Hippoglossoides elassodon & 233 & 0.7706 & 0.0016 & 0.9306 \\
\hline Pacific halibut & Hippoglossus stenolepis & 205 & 0.1705 & 0.7610 & 0.0036 \\
\hline Rock sole & Lepidopsetta spp. & 253 & 0.2309 & 0.0230 & 0.0668 \\
\hline Yellowfin sole & Limanda aspera & 199 & 0.0308 & 0.0284 & 0.0008 \\
\hline Alaska plaice & Pleuronectes quadrituberculatus & 200 & 0.0077 & 0.0089 & 0.0374 \\
\hline Sturgeon poacher & Podothecus accipenserinus & 168 & 0.0483 & 0.3694 & 0.5142 \\
\hline Skates & Rajidae & 232 & 0.0244 & 0.8748 & 0.4305 \\
\hline
\end{tabular}


2012). To ensure comparability among years, missing bottom temperature data $(4.3 \%$ of total) were estimated through multiple imputation prior to analysis (Schafer 1997). Annual mean sampling dates on the trawl survey occurred over a range of $33 \mathrm{~d}$. Because bottom temperature shows a strong seasonal evolution, the effect of sampling date must be corrected to allow valid among-year comparisons of bottom temperature. This was accomplished by fitting a nonparametric regression using penalized regression splines with the package 'mgcv' in the computer language R (Wood 2006, R Core Team 2016) to the relationship between mean temperature and mean sampling date, and calculating corrected mean temperature as the regression residuals added to the regression intercept.

The winter SST and summer bottom temperature time series illustrate the magnitude of the 2006 to 2013 cold anomaly (Fig. 2). Mean winter SST during the anomaly was approximately $0.6^{\circ} \mathrm{C}$ lower than the 1977 to 2005 mean, and similar to the pre-1976/1977 cold period. Mean summer bottom temperatures during the cold anomaly were approximately $1^{\circ} \mathrm{C}$ lower
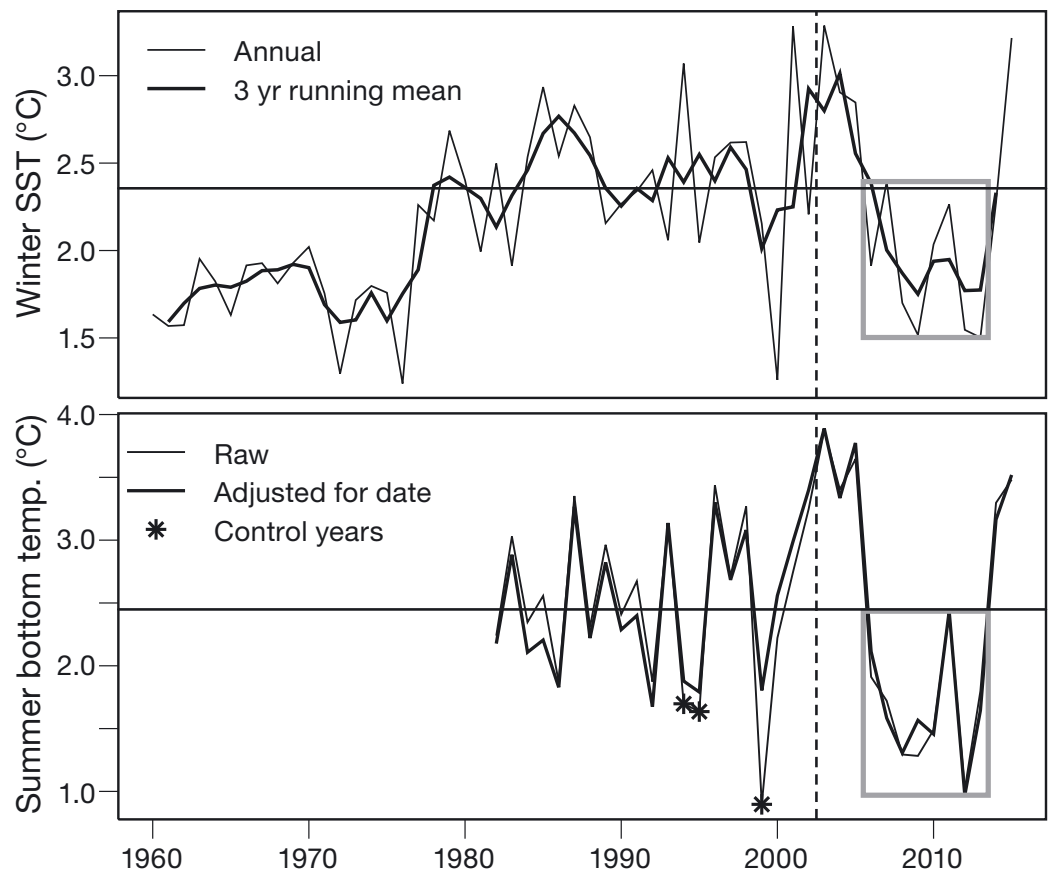

Fig. 2. Time series of Bering Sea winter (November to March) sea surface temperature (SST) from the extended reconstructed sea surface temperature (ERSST) v3b dataset (1960 to 2015, top) and summer bottom temperature from the trawl survey (1982 to 2015, bottom). Horizontal lines: post-1976/1977 mean of each time series; vertical dashed line: division between warming period (up to 2002) and cooling period (after 2002) used in tests for hysteresis. Grey boxes: data from the cold anomaly (2006 to 2013) used to test for elevated early warning signals (EWS). Stars: 'control' years for comparison with cold temperatures outside of the anomaly than during the rest of the trawl survey time series. The warmest winter in the SST time series was 2002/ 2003, and the warmest bottom temperatures were observed in summer 2003 (Fig. 2). While the warmest winter (2002/2003) was used a priori to separate the 2 periods, an analysis of the statistical differences in the slope of temperature on time using different years to distinguish the 'warming' and 'cooling' periods in the 2 temperature time series supports the designation used (see Fig. S1 in the Supplement at www. int-res.com/articles/suppl/m571p013_supp.pdf).

\section{Analysis}

\section{Question 1:}

\section{Is there evidence consistent with hysteresis?}

A schematic of the steps used in analysis is presented in Fig. 3. Hysteresis was tested for with statistical models invoking community responses (recruitment and distribution) that differed between cooling and warming periods. Community recruitment was measured with the leading axis (first principal component, PC1) of groundfish, crab, and salmon recruitment or production. This first PC score identified the well-documented response of Bering Sea taxa to the 1976/1977 warming event, and allowed testing for either reversibility of this biological response during a cooling period, or alternately, behavior consistent with hysteresis. These data were fourth-root transformed to achieve normality. Missing values $(11.7 \%$ of total) were estimated using multiple imputations with the R package 'mice' (Schafer 1997, Van Buuren \& Oudshoorn 1999). Winter SST was used as the explanatory variable for recruitment, since these data are available over the same time span as recruitment data. SST data were smoothed with a 3 yr running mean prior to analysis. The smoothing of SST data is justified by the expectation that populations are resilient to stochastic noise in environmental conditions, but sensitive to changes in the mean state (Litzow \& Mueter 2014, Litzow et al. 2014). Alternately, stronger statisti- 


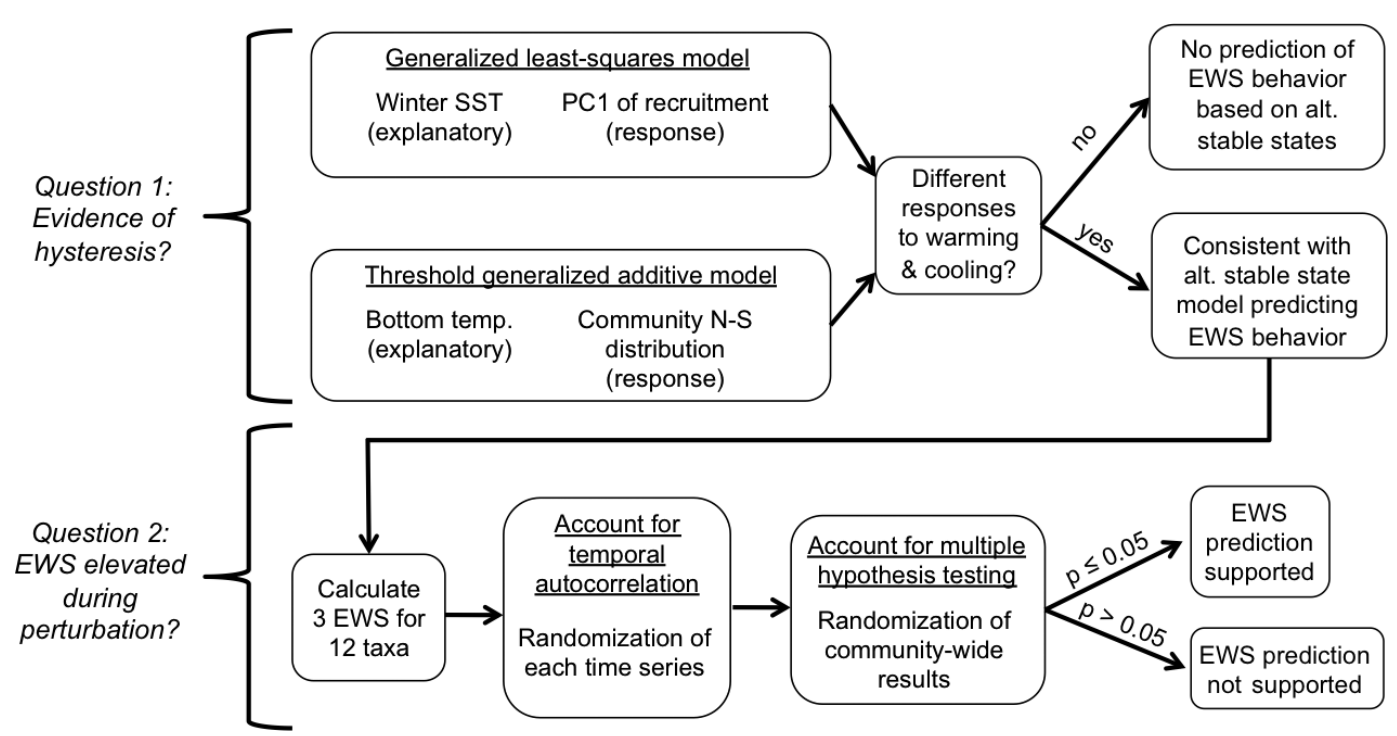

Fig. 3. Schematic of the steps used in the analysis; EWS: early warning signals; SST: sea surface temperature

cal relationships to smoothed rather than raw data may be driven by biological responses to environmental conditions that are integrated over generation times (Di Lorenzo \& Ohman 2013). Community distribution was measured with trawl survey estimates of mean latitude weighted by fourth-root transformed CPUE (i.e. center of distribution). Mean latitudes were averaged over taxa to produce a community-wide estimate of north-south distribution changes, as in Mueter \& Litzow (2008), to allow for comparison with their results.

Bottom temperature measurements from the trawl survey were used as the explanatory variable for distribution, since bottom temperature is the most important physical parameter explaining the distribution of Bering Sea demersal taxa (Mueter \& Litzow 2008, Kotwicki \& Lauth 2013). The distribution response to temperature within the warming and cooling periods was linear, so hysteresis was tested for with generalized least squares (GLS) models allowing for temporal autocorrelation in residuals (Pinheiro \& Bates 2000) and invoking main temperature and era effects and era $x$ temperature interaction effects, where 'era' refers to the warming and cooling periods. A previous study found a significant residual trend in Bering Sea community distribution which was not explained by any climate parameter examined (Mueter \& Litzow 2008). This analysis of residual trends was updated in the present study in order to further evaluate evidence for a state-dependent response to temperature.

The recruitment response to warming was sigmoidal, so the GLS model was not appropriate. In this case a threshold generalized additive model (TGAM) was used to test for hysteresis (Ciannelli et al. 2004, 2005). Briefly, the TGAM approach compares a simple GAM (Wood 2006) of the form:

$$
C=S_{1}(T)+\varepsilon
$$

with a TGAM of the form:

$$
C\left\{\begin{array}{l}
S_{1}(T)+\varepsilon \text { if trend is warming } \\
S_{2}(T)+\varepsilon \text { if trend is cooling }
\end{array}\right.
$$

where $C$ is the community response variable, $T$ is temperature, $s_{1}$ and $s_{2}$ are smooth functions, and $\varepsilon$ is an error term. The GAM (Eq. 1) models community response without hysteresis, and the TGAM (Eq. 2) models a hysteric response if the temperature values during the warming and cooling periods overlap. As in the GLS, the threshold year in the TGAM model was set a priori to $2002 / 2003$, which provided the strongest definition of distinct warming and cooling period based on trends in summer bottom temperature and winter SST (Fig. S1). The 2 models were compared with Akaike's information criterion adjusted for small sample size $\left(\mathrm{AIC}_{\mathrm{c}}\right)$ to determine which best explained the data (Burnham \& Anderson 2002).

A central expectation for the demonstration of hysteresis is that external conditions are identical during the 2 periods under consideration, with the exception that the direction of change in the external parameter is different (Beisner et al. 2003, Petraitis \& Dudgeon 2004). In order to evaluate the evidence for this expectation, a second test for behavior consistent with hysteresis was conducted on both response vari- 
ables (i.e. the first PC of recruitment and production and the average distribution of the community). This analysis assessed the broader evidence for environmental similarity between warming and cooling periods, using an expanded set of environmental parameters that have been proposed as major drivers of ecological variability in the Bering Sea (Stachura et al. 2014). The exact set of parameters depended on the availability of data at the relevant time scales. For recruitment and production variability (1960 to 2013), these parameters included winter SST, winter $U$ - and $V$-wind speed, and discharge of the Kuskokwim River during winter and summer. For distribution variability (1982 to 2015), this analysis included all of these variables plus bottom temperature, the extent of winter ice cover, the sum of commercial catch for the species under consideration, and the first PC for distribution of the commercial catch among species (both catch parameters lagged $1 \mathrm{yr}$ prior to the response). The broader set of external parameters for recruitment and production variability did not include commercial catch data since salmon production estimates (part of the response variable) are themselves derived from lagged catch data. Sources for the expanded set of environmental parameters are presented in Stachura et al. (2014).

\section{Question 2: Were EWS elevated during the cold anomaly?}

To answer this question, evidence of elevated EWS during the cold anomaly and false positive EWS were tested for. The 3 EWS used were increased spatial variability, increased spatial autocorrelation, and increased temporal autocorrelation. The standard deviation of log-transformed CPUE (SDL; calculated over stations within a year) was used to measure spatial variability. Trawl survey CPUE data are typically skewed, and SDL is robust to skewness in the underlying data (McArdle et al. 1990, Fraterrigo \& Rusak 2008). Moran's I (Moran 1950), weighted by the inverse of distance among stations, was used to measure spatial autocorrelation in CPUE. First-order temporal autocorrelation, AR(1), was calculated as Pearson's correlation coefficient for CPUE values in years $t$ and $t-1$ for stations where a taxon was caught in consecutive years. The $34 \mathrm{yr}$ time series in this study was judged too short for the calculation of trends in temporal variability using moving windows within the time series data.

An initial examination of data for the 35 most common taxa targeted by the trawl survey showed strong log-log relationships between mean annual sample size (average annual count of stations where present) and variability (coefficient of variation) for each of the 3 EWS ( $p<0.0001 ;$ Fig. S2 in the Supplement). Ecological noise is an important hurdle for the successful application of EWS in actual ecosystems (Lindegren et al. 2012, Perretti \& Munch 2012, Litzow et al. 2013). Accordingly, variability in EWS was minimized by restricting analysis to taxa with a mean annual sample size $\geq 150$. This criterion limited analysis to 12 taxa (sample sizes in Table 1).

Temporal autocorrelation in EWS time series violated the assumption of independent observations, so a Monte Carlo approach (Manly 2006) was used to test for increased EWS values during the cold anomaly (2006 to 2013) compared with warm years (1982 to 2005, 2014/2015). For each EWS time series, the actual $t$-value from the cold versus warm comparison was compared with $t$-values from 10000 random permutations of the same length with first-order autocorrelation equal to that actually observed in the EWS time series. The probability of observed results under the null hypothesis was estimated as the proportion of permutations with a $t$-value equal to or more extreme (lower) than the observed value (Manly 2006). This test was 1-tailed because our alternate hypothesis predicted elevated EWS values during the cold anomaly.

Because multiple hypothesis tests were conducted (12 taxa $\times 3$ EWS $=36$ total combinations), the analysis suffered from the possibility of an elevated Type I error rate. This problem was addressed with a community-wide Monte Carlo approach to assess the probability of obtaining the overall results under the null hypothesis of no EWS increase during the cold anomaly for all 12 taxa considered. This test used 10000 random permutations of the 36 taxon $\times$ EWS combinations at levels of autocorrelation observed in the original data. In each permutation of the 36 time series, the number of significant results $(p \leq 0.05)$ was recorded, and the probability of obtaining observed results under the null hypothesis was calculated as the proportion of the 10000 permutations resulting in as many (or more) rejections of the null hypothesis as observed in the actual data. None of the pairwise correlations among EWS time series were significant after false discovery rate control (Verhoeven et al. 2005) and control for temporal autocorrelation with the Modified Chelton method (Pyper \& Peterman 1998). This lack of significant relationships among time series justified the community-wide randomization approach without consideration of intercorrelation among EWS time series. 
A number of taxa sampled in the Bering Sea trawl survey show changes in distribution during cold years, in particular in response to increased extent of the 'cold pool' of bottom water $<1^{\circ} \mathrm{C}$ (Mueter \& Litzow 2008, Kotwicki \& Lauth 2013). Additionally, a number of taxa may show behavioral changes during cold periods (e.g. burying in bottom sediment, delayed seasonal migration) that may make them less available to sampling gear (Stevenson \& Lauth 2012). Accordingly, there is the possibility that EWS statistics derived from CPUE data might produce false positives by responding directly to temperature variability rather than to changes in community resilience per se. For instance, distribution for some taxa might be more spatially variable in cold conditions, regardless of changes in resilience. The hypothesis that elevated EWS during the cold anomaly were false positive signals related to direct temperature effects, rather than declining resilience and critical slowing down, was tested by comparing EWS during the cold anomaly with EWS from a control group of the 3 years of lowest observed raw bottom temperature outside of the cold anomaly $(1994,1995,1999)$. This analysis used raw bottom temperature (uncorrected for sampling date) because the effects of temperature at the time of sampling on EWS were of interest.

\section{RESULTS \\ Question 1: \\ Is there evidence consistent with hysteresis?}

The first PC of recruitment time series explained $39 \%$ of total variance, and showed the strongest loadings on Greenland halibut (0.49), Tanner crab (0.46), chum salmon $(-0.36)$, sockeye salmon $(-0.52)$, and coho salmon (-0.39). The TGAM model invoking different responses during the warming and cooling eras $\left(\mathrm{AIC}_{\mathrm{C}}=150.9\right)$ was much better than the GAM invoking a single response of recruitment to SST across the entire time series $\left(\mathrm{AIC}_{\mathrm{C}}=174.8\right)$, indicating strong support for a model of separate community responses to warming and cooling, below $\sim 2.2^{\circ} \mathrm{C}$ (Fig. 4). Plots for individual species showed that Chinook, coho, and sockeye salmon, Tanner crab, and walleye pollock all showed state-dependent relationships with SST that were consistent with hysteresis (Fig. S3 in the Supplement). Analysis with SST, wind speed, and river inputs also showed a state-dependent response of community-wide recruitment to the overall variation in this broader set of environmental

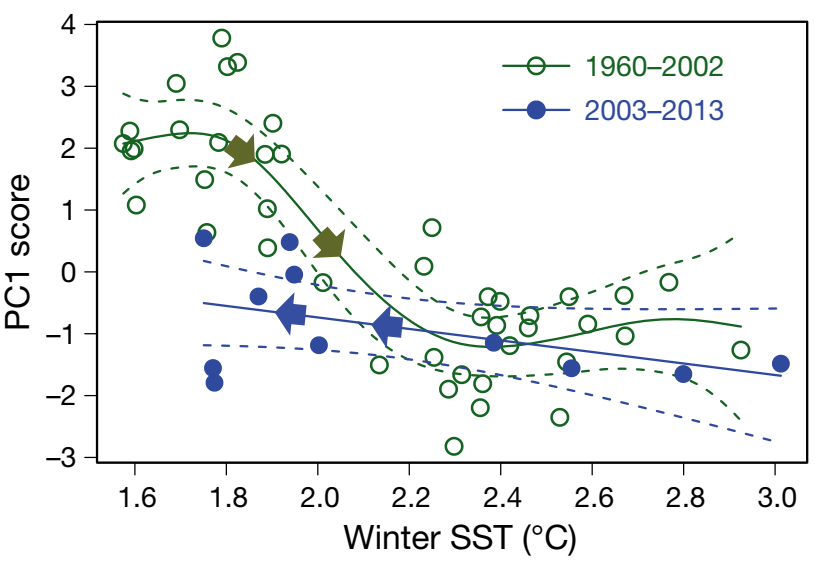

Fig. 4. Indications of hysteresis in response of community recruitment patterns to sea surface temperature (SST). Plot shows change in the leading axis of recruitment variability for 10 taxa (PC1 score) during warming period (1960 to 2002, green open circles) and subsequent cooling period (2003 to 2013, blue filled circles). Arrows on regression lines: predominant direction of temperature change in each period; dashed lines: $95 \%$ CI around regressions. The plotted threshold generalized additive model (TGAM) was superior to a nonhysteresis model of PC1-SST relationships $\left(\triangle \mathrm{AIC}_{\mathrm{c}}=23.8\right)$

variables (Fig. S4 in the Supplement; with the TGAM model outperforming the GAM model, $\left.\Delta \mathrm{AIC}_{\mathrm{C}}=18.5\right)$.

The GLS test of era effects on the temperaturedistribution relationship found a significant effect of both era $(p=0.0001)$ and the era $\times$ temperature interaction ( $p=0.0002)$. Thus, community distribution appeared to respond to temperature change differently during the warming and cooling periods (Fig. 5a). Similar results were obtained using raw temperature, unadjusted for sampling date (data not shown). Analysis with the broader set of external parameters, including commercial fishing effects and the more extensive set of climate patterns, produced an inferior model for explaining variability in distribution when compared with the model invoking only bottom temperature as a covariate $\left(\Delta \mathrm{AIC}_{\mathrm{c}}=26.9\right)$. Neither the era effect $(p=0.08)$ nor the era $\times$ PC1 effect ( $p=0.09$ ) were significant in the model invoking the broader set of covariates (Fig. S5 in the Supplement). The stronger performance of the simpler model invoking only bottom temperature is consistent with the view that distribution of demersal taxa in the Bering Sea is specifically driven by bottom temperature, rather than the broader measures of ecosystem state (Wyllie-Echeverria \& Wooster 1998, Mueter \& Litzow 2008, Kotwicki \& Lauth 2013).

Residuals from the temperature-distribution relationship during 1982 to 2006 were previously noted to show a rising trend, which was ascribed to internal community dynamics (Mueter \& Litzow 2008). Up- 

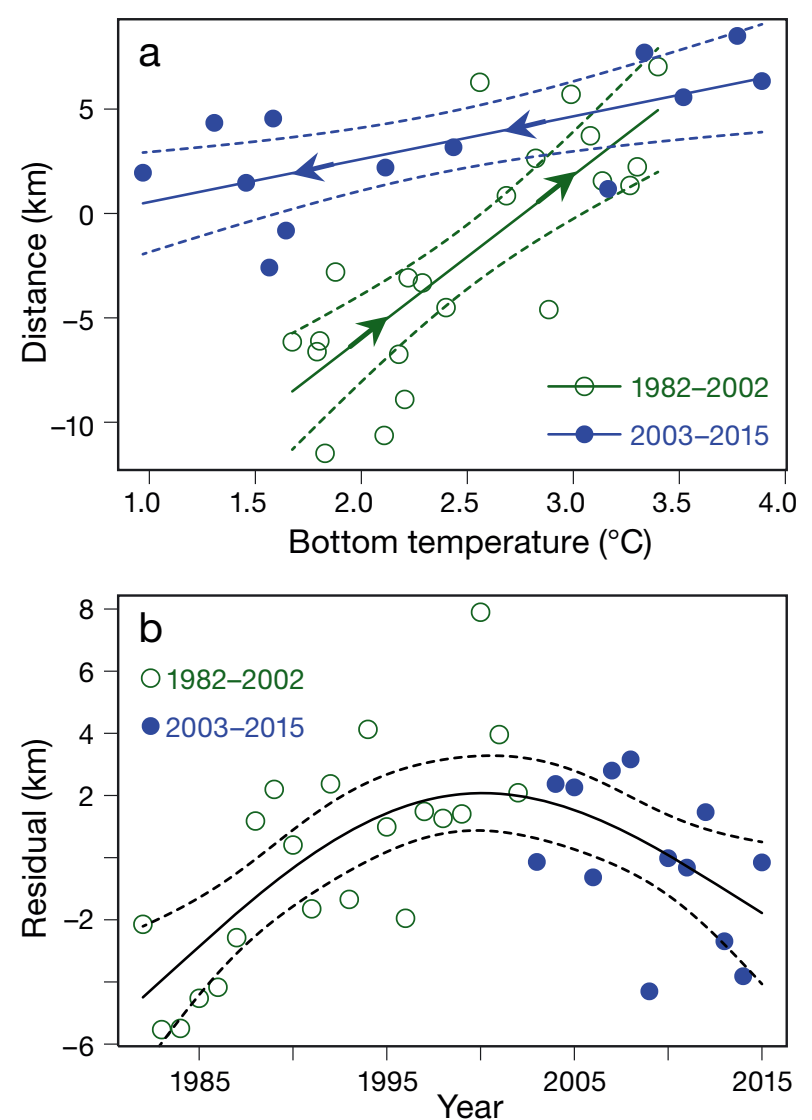

Fig. 5. Indications of hysteresis in response of community distribution to bottom temperature. (a) Change in the average center of distribution (distance from mean latitude, averaged across 12 taxa) during warming period (1982 to 2002, green) and subsequent cooling period (2003 to 2015, blue). Arrows on regression lines: predominant direction of temperature change in each period. (b) Change in nonlinear dynamics between warming and cooling period: annual residuals from regressions in (a). Dashed lines: $95 \%$ CI around regressions

dated analysis of the trend in residuals from the temperature-distribution relationship during 1982 to 2015 shows a decline in residual values during the cooling period, creating a highly significant domeshaped trend throughout the time series $\left(\mathrm{GAM}_{i} \mathrm{R}^{2}=\right.$ $0.43, p=0.0003$; Fig. 5b). Together, the results in Figs. 4 \& 5 and Fig. S4 support the conclusion that the Bering Sea community showed evidence consistent with hysteresis during the cold anomaly.

\section{Question 2:}

\section{Were EWS elevated during the cold anomaly?}

Randomization tests resulted in p-values $\leq 0.05$ for 15 of the 36 EWS examined (Table 1). Three taxa (Alaska plaice, walleye pollock, yellowfin sole) showed p-values $\leq 0.05$ for all 3 EWS (Fig. 6). The result of 15 rejected null hypotheses out of 36 total was not repeated in the 10000 community-wide permutations ( $p<0.0001$; Fig. 7$)$, indicating that the EWS during the cold anomaly were not Type I errors, but did signal declining community resilience. Complete time series for all EWS are presented in Tables S1 to S3 in the Supplement.

Raw bottom temperatures were slightly lower during the 'control' years for tests for false positive EWS $(1994,1995,1999)$ than during the cold anomaly (control mean $\pm \mathrm{SE}$ : $1.41 \pm 0.26^{\circ} \mathrm{C}_{i}$ cold anomaly mean \pm SE: $1.62 \pm 0.16^{\circ} \mathrm{C}$ ). The 'control' years were therefore an honest comparison in the test for temperature effects per se on EWS behavior. However, in spite of the greater cold during the control period, the 3 EWS were lower during the control period than during the cold anomaly (Wilks' $\lambda=0.79, \mathrm{p}<0.00001$; Fig. 8). This result leads to rejection of the hypothesis that elevated EWS during the cold anomaly were false positives driven purely by cold-mediated changes to distribution or behavior.
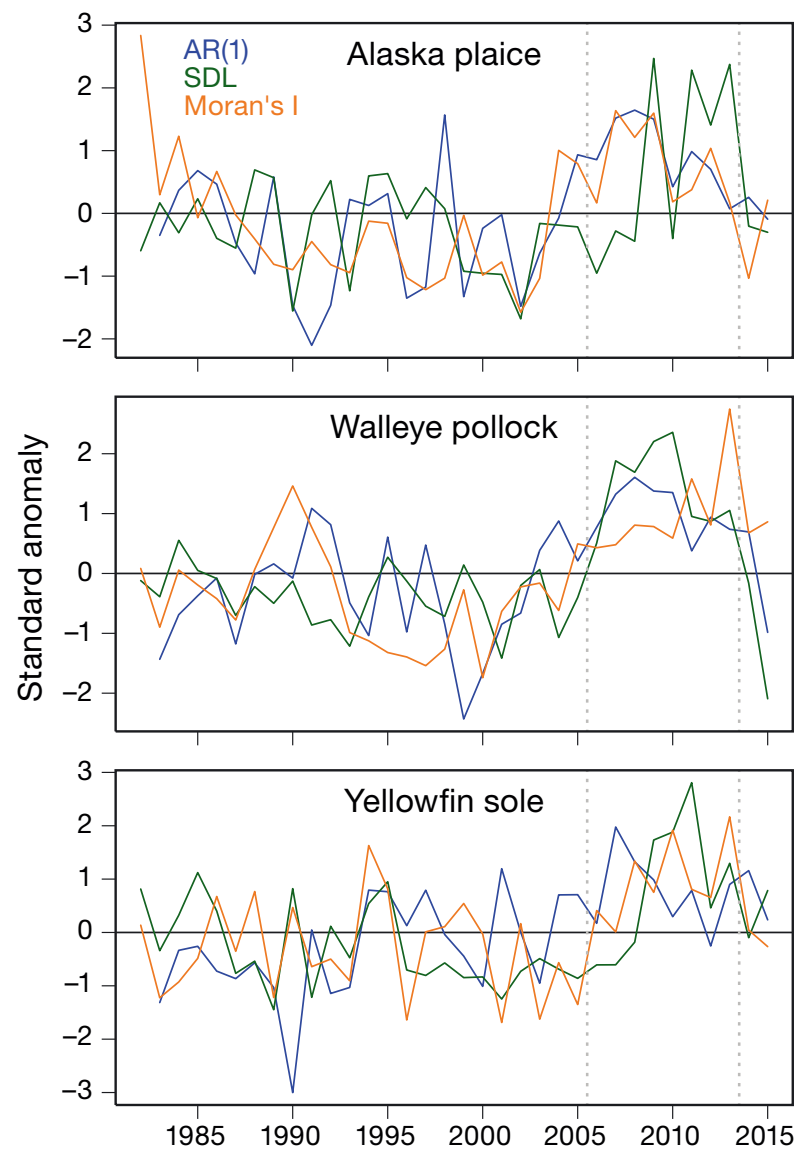

Fig. 6. Early warning signal time series for taxa showing 3 significant increases during cold anomaly. Vertical dashed lines: cold anomaly (lines at 2005.5, 2013.5). All time series standardized as mean 0 , unit variance 


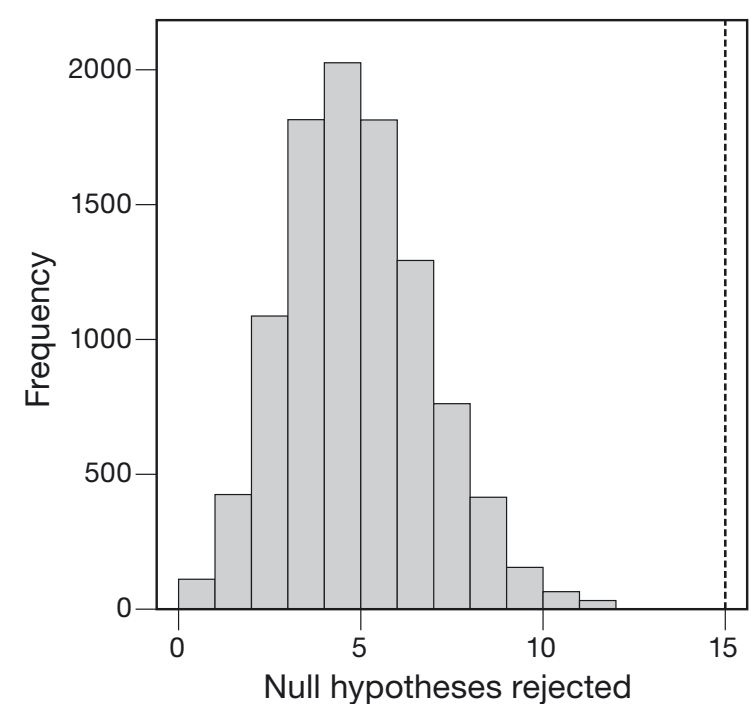

Fig. 7. Results of 10000 community-wide randomizations testing null hypothesis of no increase in early warning signals (EWS) during cold anomaly: number of individual null hypotheses rejected at $\mathrm{p} \leq 0.05$ out of 36 total taxon $\times$ EWS combinations. Observed result (15 null hypotheses rejected) indicated by dashed vertical line

\section{DISCUSSION}

The Bering Sea cold anomaly offers an empirical example that is consistent with theoretical predictions for EWS. Community-level patterns of recruitment variability (Fig. 4) and distribution (Fig. 5) showed statistical evidence of temperature responses that differed between periods of warming and cooling, and these results were repeated with analysis of recruitment variability using a broader set of external parameters (Fig. S4 in the Supplement). These observations are consistent with hysteresis, and therefore provide reasonably strong indications that alternative stable states may operate in this system (Dudgeon et al. 2010, Petraitis \& Hoffman 2010, Wang et al. 2012). The alternative stable state model then predicts that elevated EWS should be observed in the warm community state under the persistent perturbation of the cold anomaly; this prediction was well supported (Table 1). The observation of significantly elevated values in 15 of 36 individual EWS time series is extremely unusual under the null hypothesis of no decline in community resilience (Fig. 7), and these increases in EWS are not consistent with a response to cold per se (Fig. 8). These results are consistent with a decline in community-level resilience under the persistent perturbation of the cold anomaly, and this community-level approach to EWS monitoring is consis-

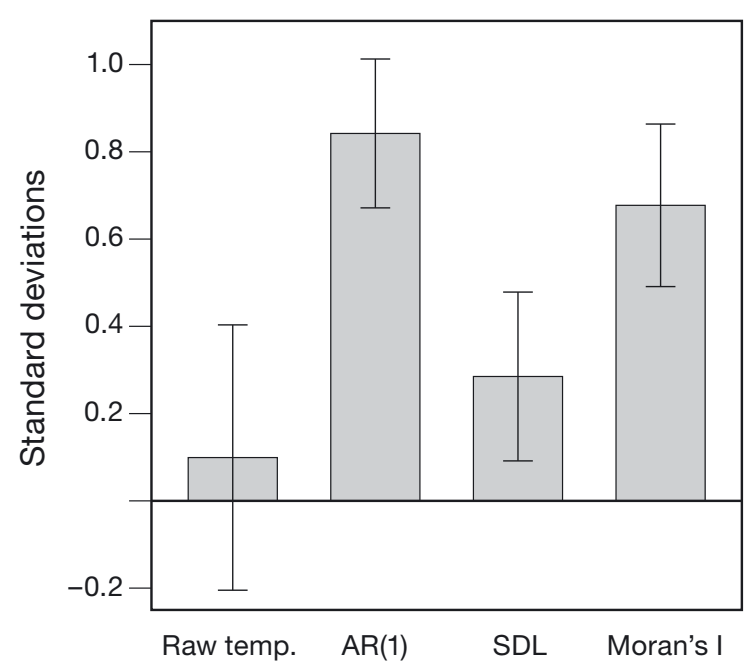

Fig. 8. Comparison between cold anomaly (2006 to 2013) and 'control' of 3 other cold years $(1994,1995,1999)$ : coefficients from analysis of variance. Raw temperature (unadjusted for sampling date) was similar between the cold anomaly and 'control' years, but early warning signals were significantly higher during the cold anomaly (Wilks' $\lambda=0.79$, $\mathrm{p}<0.00001$ ). Plotted values are coefficients for comparison of cold anomaly with 'control' years \pm SE. All data standardized as 0 mean, unit variance

tent with the strong community-level responses to temperature variability in the system (Figs. 4 \& 5). While differences in EWS among species were observed (Table 1), the mechanisms driving these specieslevel differences are beyond the scope of this study, and likely require more detailed understanding of complex ecological dynamics in the Bering Sea than currently exists (Mueter \& Litzow 2008, Litzow \& Hunsicker 2016).

The strength of inference generated by these observations is limited by the fact that a critical transition from the warm community state to the cold community state did not occur. If the alternate stable state model does apply to this system, the cold anomaly perturbation was presumably too short or not severe enough to force the system through a critical transition. Most empirical studies of EWS have concentrated on retrospective tests for elevated EWS prior to historical ecosystem shifts (Boettiger \& Hastings 2012a, Wouters et al. 2015). By elucidating the type of model that may operate in the study system, and then testing predictions concerning the operation of EWS arising from that model, this study offers a complementary approach for empirical EWS research. A central question for the application of EWS as a management tool is whether the nonlinear ecological models underlying EWS theory are actually applicable in the large, complex systems that are of 
interest to managers (Litzow \& Hunsicker 2016). By demonstrating support for theoretical predictions concerning EWS behavior under persistent perturbation, this study helps to demonstrate the applicability of EWS theory to complex ecosystems, and may thus contribute to the evaluation of the reliability of EWS for providing managers with early indication of impending ecosystem shifts. The results of this study agree with previous studies from Alaska that have found elevated EWS prior to historical shifts in trawl surveys and fisheries catches (Litzow et al. 2008, 2013). These results are also consistent with a metaanalysis showing that EWS are more likely to be supported in empirical studies when behavior consistent with nonlinear ecological models, including hysteresis, is present (Litzow \& Hunsicker 2016).

The magnitude of ecosystem services provided by the eastern Bering Sea, and the stakes for managing the system correctly, are enormous. Annual ex-vessel prices for groundfish and salmon fisheries exceed one billion US dollars (www.npfmc.org, www.adfg.alaska. gov). In general, eastern Bering Sea fisheries are sustainably and conservatively managed (Witherell et al. 2000, Ianelli 2005, but see Hilborn 2006, Loring 2013). However, with the notable exception of the cold anomaly considered in this study, climate variability and anthropogenic climate change have produced rapid warming in the eastern Bering Sea over recent decades; the linear trend fit to annual winter SST data in Fig. 2 is statistically significant (GLS model accounting for temporal autocorrelation, $\mathrm{p}=0.03$ ) and shows an increase of $0.64^{\circ}$ between 1960 and 2015 . The system is therefore being progressively pushed from the set of conditions under which ecological understanding and fisheries management have developed, with the attendant possibility of an 'ecological surprise' outside of our current understanding (Doak et al. 2008). This possibility is certainly not lost on scientists and fishery managers, and there is a great deal of interest in developing scientific advice for managing the Bering Sea ecosystem under climate change (Haynie \& Pfeiffer 2013, Hollowed et al. 2013). However, current approaches for monitoring the status of the ecosystem rely entirely on tracking parameter means, or other statistics of central tendency (Zador 2015). While the utility of EWS is still open to debate, there is a strong consensus among ecologists that monitoring mean system state alone is likely inadequate in systems showing nonlinear responses to perturbation, as mean values may reveal ecological changes only after these changes have become firmly entrenched (Folke et al. 2004). By demonstrating the response of EWS to a perturbation, and by defining baseline levels of EWS derived from the trawl survey (see Tables S1 to S3 in the Supplement), this study lays the foundation for introducing EWS into the ecosystem monitoring program for the eastern Bering Sea. 'Promoting sustainable fisheries and communities' is an identified goal for EBFM in the Bering Sea (Hollowed et al. 2011). Tracking changes to resilience through EWS is a way to determine if that goal is being achieved.

The results of this study apply only to regime shifts in a narrowly defined sense-as critical transitions between alternative states in the fold bifurcation model. The 'regime shift' is something of a blanket concept, suffering from the lack of a universally accepted definition, and sudden shifts that may have arisen from many different types of underlying dynamics have been labeled with the term (Lees et al. 2006, Litzow \& Mueter 2014, Conversi et al. 2015). The results of this study should not be generalized beyond the narrowly-defined class of regime shift considered here. In particular, red noise processes (i.e. random, autocorrelated noise) may drive many high-profile 'regime shifts' in marine ecosystem time series (Rudnick \& Davis 2003, Di Lorenzo \& Ohman 2013). While it is possible that EWS may precede such shifts (Kéfi et al. 2013), this possibility has received less theoretical support than EWS arising from the fold bifurcation model (Dakos et al. 2015).

These results indicate that the application of EWS to large ecosystems, using observational datasets, deserves continued research in spite of negative results in other studies (e.g. Bestelmeyer et al. 2011, Lindegren et al. 2012, Burthe et al. 2016). A particular challenge for empirical studies is that EWS, as they are currently developed, can only give managers a warning that some sort of shift is becoming more likely, without providing any information about the nature or timing of the shift (Dakos et al. 2015). In this example, an intuitive interpretation is that increased EWS were an indication that a sudden switch back to the cold community state became more likely during the cold anomaly. For directional climate change, where the system is progressively being pushed away from previously observed conditions, similar inferences based on system history will be less useful. In these situations, it may be more practical to attempt to use EWS for information about the timing of a potential shift, rather than its nature. Drake \& Griffen (2010) related the magnitude of EWS signals (in units of SD) to the time remaining until a shift in experimentally manipulated Daphnia populations under laboratory conditions. Developing similar reference points for EWS in the statistically noisier 
natural world, where EWS cannot be studied in the absence of confounding factors, will require that results be compared across many studies.

This study offers some guidance for the methods used in empirical EWS research. Although the length of the trawl survey time series used here compares favorably with the length of time series available for most marine ecosystems, the $34 \mathrm{yr}$ time series was too short for the calculation of temporal EWS, such as variability or autocorrelation, over sliding windows (Bestelmeyer et al. 2011, Wang et al. 2012). Spatial indicators may generally be preferable to temporal indicators in data-limited situations, as they can be calculated within each time step in the data without reference to sliding windows, and because they may offer longer warning of an impending shift in the system than EWS calculated with sliding windows (Guttal \& Jayaprakash 2009, Dakos et al. 2010). The Bering Sea survey, with 285 stations sampled in every year (Fig. 1), provides an excellent basis for calculating spatial EWS. Trawl survey data are available in a number of other marine ecosystems globally, and these time series are appealing candidates for EWS research. In addition to using spatial EWS, this study also used temporal autocorrelation calculated as the correlation coefficient for CPUE values at stations where a taxon was present during consecutive years, rather than as first-order autocorrelation over a sliding window. This approach may be useful for the application of temporal autocorrelation without the liabilities associated with sliding windows. Tests for false positives (Fig. 8) are important for generating the confidence in EWS that will be required for their uptake by managers (Boettiger \& Hastings 2012b). Finally, the high levels of EWS noise in this study (e.g. time series in Fig. 6) could be countered by considering the relationship between sample size and variability (Fig. S2) and by conducting tests across multiple populations (Table 1, Fig. 7). This approach corroborates earlier studies that have noted the importance of conducting multiple EWS tests to counter noise (Lindegren et al. 2012, Litzow et al. 2013).

The finding that the eastern Bering Sea community may show hysteresis also has implications for understanding ecological responses to climate change. In traditional statistical approaches, the relationships between climatic and biological variables are assumed to be time-invariant, and this assumption is rarely evaluated (Ciannelli et al. 2012, Schmidt et al. 2014, Ye et al. 2015). However, time-evolving, statedependent driver-response relationships, as shown here, are a common feature of ecosystems (Deyle et al. 2013). Failure to account for these state-dependent driver-response relationships may impair ecological understanding, and may result in overly simplistic advice to managers, such as an expectation of a reversion to earlier biological properties upon the resumption of a multi-year cold period in the Bering Sea.

Understanding the mechanisms underlying apparent hysteresis (Figs. 4 \& 5) is therefore critical for complete understanding of eastern Bering Sea dynamics. Community resilience increases with diversity (Frank et al. 2006), and warming since the 1980s has increased diversity of the Bering Sea demersal community (Mueter \& Litzow 2008). This increase in diversity may therefore explain the apparent hysteresis in the community response to temperature as diversity-driven differences in resilience of the cold and warm community states. Beyond this general observation, understanding of the eastern Bering Sea ecosystem is not advanced enough to provide a mechanistic understanding of possible hysteresis in the system. While the eastern Bering Sea is an extremely well-studied ecosystem, mechanistic studies typically occur on temporal scales of 3 to $5 \mathrm{yr}$ and are therefore too short to allow investigation of nonstationary driver-response relationships at decadal time scales. Studies using trawl survey data from other ecosystems to evaluate species interactions that are believed to drive alternative stable state dynamics suggest a possible approach for expanding this mechanistic understanding in the Bering Sea (Huss et al. 2013, Gårdmark et al. 2015). Previous analysis for 1982 to 2006, when the trend in temperaturedistribution residuals was monotonically rising, failed to find any relationship between the residual trend and a suite of non-temperature climate parameters (Mueter \& Litzow 2008), although the effects of other external forcings on the system (e.g. commercial fishing; Litzow et al. 2014) or internal forcings (e.g. density dependence; Spencer 2008, Kotwicki \& Lauth 2013) were not examined. The updated analysis, showing a dome-shaped pattern in these residuals across the warming and cooling eras (Fig. 5b) hints at strong nonlinearities in community dynamics, though the underlying mechanisms remain unclear. This pattern in temperature-distribution residuals indicates increasing temperature effects during the warming period, and declining effects of temperature during the cooling period. This result, and the failure of recruitment PC1 to retrace the sigmoidal temperature effect during the cooling era (Fig. 4) suggest a 'ratchet' response to temperature change in the system, where warming effects are not reversed by subsequent cooling. 
Finally, there are some important theoretical caveats concerning the interpretation of these results. Although the fold bifurcation model is often invoked for studies of EWS, versions of this model can in fact fail to produce EWS prior to a critical transition (Boerlijst et al. 2013). Aligning a study system with the alternative state model is therefore no guarantee that shifts in that system will be preceded by EWS. Additionally, while evidence of hysteretic driver-response relationships is often taken as evidence of alternative states, this need not be the case. Asymmetry in a single basin of attraction may produce apparent hysteresis in the absence of alternative states (Beisner et al. 2003). Demonstrating alternative states also requires observation of dual biological states at identical levels of external conditions (Petraitis \& Dudgeon 2004). Though this condition was supported through a test involving a broader set of climatic and exploitation-related parameters (Fig. S4), guaranteeing literally identical conditions over time is impossible in any large ecosystem.

To a large extent, these caveats represent the limitations inherent in observational studies of complex ecological dynamics, where variability due to uncontrolled or unexamined variables is inevitable, and alternate interpretations of results are difficult to rule out. In spite of these limitations, observational studies are necessary for evaluating the utility of EWS in large ecosystems where controlled experiments are impossible. Testing for evidence of hysteresis and elevated EWS allowed me to confront model predictions with the data that are available from this system, and these results are one indication of how EWS theory might work in the real world. Ultimately, determining the degree to which complex systems such as the Bering Sea are successfully described by theoretical predictions for EWS will require the combined results of many such studies.

Acknowledgements. I thank the many biologists and boat crews who collected the trawl survey data used in this study, and the authors of stock assessments that were used to derive recruitment time series. Bob Lauth provided important input on the study design and analysis, Franz Mueter provided much of the R code used in the analysis, and Anna Gårdmark, Mary Hunsicker, Bob Lauth, and 2 anonymous reviewers made helpful comments on earlier versions of the paper. The ERSST dataset was made publicly available by the NOAA National Centers for Environmental Information, USA. This research was funded by Alaska Sea Grant (project R/31-24) with funds from the NOAA Office of Sea Grant, US Department of Commerce.

\section{LITERATURE CITED}

Anderson PJ, Piatt JF (1999) Community reorganization in the Gulf of Alaska following ocean climate regime shift. Mar Ecol Prog Ser 189:117-123

*Beisner BE, Haydon DT, Cuddington K (2003) Alternative stable states in ecology. Front Ecol Environ 1:376-382

* Benson AJ, Trites AW (2002) Ecological effects of regime shifts in the Bering Sea and eastern North Pacific Ocean. Fish Fish 3:95-113

* Bestelmeyer BT, Ellison AM, Fraser WR, Gorman KB and others (2011) Analysis of abrupt transitions in ecological systems. Ecosphere 2:art129

Boerlijst MC, Oudman T, de Roos AM (2013) Catastrophic collapse can occur without early warning: examples of silent catastrophes in structured ecological models. PLOS ONE 8:e62033

*Boettiger C, Hastings A (2012a) Early warning signals and the prosecutor's fallacy. Proc R Soc B 279:4734-4739

* Boettiger C, Hastings A (2012b) Quantifying limits to detection of early warning for critical transitions. J R Soc Interface 9:2527-2539

Burnham KP, Anderson DR (2002) Model selection and multimodel inference: a practical information-theoretic approach. Springer-Verlag, New York, NY

* Burthe SJ, Henrys PA, Mackay EB, Spears BM and others (2016) Do early warning indicators consistently predict nonlinear change in long-term ecological data? J Appl Ecol 53:666-676

* Carpenter SR, Brock WA (2006) Rising variance: a leading indicator of ecological transition. Ecol Lett 9:311-318

* Carpenter SR, Cole JJ, Pace ML, Batt R and others (2011) Early warnings of regime shifts: a whole-ecosystem experiment. Science 332:1079-1082

* Ciannelli L, Chan KS, Bailey KM, Stenseth NC (2004) Nonadditive effects of the environment on the survival of a large marine fish population. Ecology 85:3418-3427

Ciannelli L, Bailey KM, Chan KS, Belgrano A, Stenseth NC (2005) Climate change causing phase transitions of walleye pollock (Theragra chalcogramma) recruitment dynamics. Proc R Soc B 272:1735-1743

* Ciannelli L, Bartolino V, Chan KS (2012) Non-additive and non-stationary properties in the spatial distribution of a large marine fish population. Proc R Soc B 279: 3635-3642

* Conners ME, Hollowed AB, Brown E (2002) Retrospective analysis of Bering Sea bottom trawl surveys: regime shift and ecosystem reorganization. Prog Oceanogr 55:209-222

Conversi A, Dakos V, Gårdmark A, Ling S and others (2015) A holistic view of marine regime shifts. Philos Trans R Soc Lond B Biol Sci 370:20130279

* Dai L, Vorselen D, Korolev KS, Gore J (2012) Generic indicators for loss of resilience before a tipping point leading to population collapse. Science 336:1175-1177

* Dakos V, van Nes EH, Donangelo R, Fort H, Scheffer M (2010) Spatial correlation as leading indicator of catastrophic shifts. Theor Ecol 3:163-174

* Dakos V, Carpenter SR, van Nes EH, Scheffer M (2015) Resilience indicators: prospects and limitations for early warnings of regime shifts. Philos Trans R Soc Lond B Biol Sci 370:20130263

* Deyle ER, Fogarty M, Hsieh CH, Kaufman L and others (2013) Predicting climate effects on Pacific sardine. Proc Natl Acad Sci USA 110:6430-6435

* Di Lorenzo E, Ohman MD (2013) A double-integration 
hypothesis to explain ocean ecosystem response to climate forcing. Proc Natl Acad Sci USA 110:2496-2499

Doak DF, Estes JA, Halpern BS, Jacob U and others (2008) Understanding and predicting ecological dynamics: Are major surprises inevitable? Ecology 89:952-961

Drake JM, Griffen BD (2010) Early warning signals of extinction in deteriorating environments. Nature 467:456-459

Wudgeon SR, Aronson RB, Bruno JF, Precht WF (2010) Phase shifts and stable states on coral reefs. Mar Ecol Prog Ser 413:201-216

Essington TE, Punt AE (2011) Implementing ecosystembased fisheries management: advances, challenges and emerging tools. Fish Fish 12:123-124

Folke C, Carpenter S, Walker B, Scheffer M, Elmqvist T, Gunderson L, Holling CS (2004) Regime shifts, resilience, and biodiversity in ecosystem management. Annu Rev Ecol Evol Syst 35:557-581

Frank KT, Petrie B, Shackell NL, Choi JS (2006) Reconciling differences in trophic control in mid-latitude marine ecosystems. Ecol Lett 9:1096-1105

Fraterrigo JM, Rusak JA (2008) Disturbance-driven changes in the variability of ecological patterns and processes. Ecol Lett 11:756-770

Gårdmark A, Casini M, Huss M, van Leeuwen A, Hjelm J, Persson L, de Roos AM (2015) Regime shifts in exploited marine food webs: detecting mechanisms underlying alternative stable states using size-structured community dynamics theory. Philos Trans R Soc Lond B Biol Sci 370: 20130262

Guttal V, Jayaprakash C (2009) Spatial variance and spatial skewness: leading indicators of regime shifts in spatial ecological systems. Theor Ecol 2:3-12

Hare SR, Mantua NJ (2000) Empirical evidence for North Pacific regime shifts in 1977 and 1989. Prog Oceanogr 47: 103-145

Hare SR, Mantua NJ, Francis RC (1999) Inverse production regimes: Alaskan and West Coast salmon. Fisheries (Bethesda, Md) 24:6-14

Hastings A, Wysham DB (2010) Regime shifts in ecological systems can occur with no warning. Ecol Lett 13:464-472

Haynie AC, Pfeiffer L (2013) Climatic and economic drivers of the Bering Sea walleye pollock (Theragra chalcogramma) fishery: implications for the future. Can J Fish Aquat Sci 70:841-853

Hilborn R (2006) Fisheries success and failure: the case of the Bristol Bay salmon fishery. Bull Mar Sci 78:487-498

* Hollowed AB, Hare SR, Wooster WS (2001) Pacific Basin climate variability and patterns of Northeast Pacific marine fish production. Prog Oceanogr 49:257-282

Hollowed AB, Aydin KY, Essington TE, Ianelli JN, Megrey BA, Punt AE, Smith ADM (2011) Experience with quantitative ecosystem assessment tools in the northeast Pacific. Fish Fish 12:189-208

Hollowed AB, Barange M, Beamish RJ, Brander K and others (2013) Projected impacts of climate change on marine fish and fisheries. ICES J Mar Sci 70:1023-1037

Hunsicker ME, Kappel CV, Selkoe KA, Halpern BS, Scarborough C, Mease L, Amrhein A (2016) Characterizing driver-response relationships in marine pelagic ecosystems for improved ocean management. Ecol Appl 26: 651-663

KHuss M, de Roos AM, Van Leeuwen A, Casini M, Gårdmark A (2013) Cohort dynamics give rise to alternative stable community states. Am Nat 182:374-392

Ianelli J (2005) Assessment and fisheries management of eastern Bering Sea walleye pollock: Is sustainability luck? Bull Mar Sci 76:321-335

Isaacs JD (1975) Some ideas and frustrations about fishery science. CCOFI Rep 28:34-43

Kéfi S, Dakos V, van Nes EH, Rietkerk M (2013) Early warning signals also precede non-catastrophic transitions. Oikos 122:641-648

Kotwicki S, Lauth RR (2013) Detecting temporal trends and environmentally-driven changes in the spatial distribution of bottom fishes and crabs on the eastern Bering Sea shelf. Deep Sea Res II 94:231-243

Lauth RR, Nichol DG (2013) Results of the 2012 eastern Bering Sea bottom trawl survey of groundfish and invertebrate resources. NOAA Tech Memo NMFS-AFSC-256, US Department of Commerce, Springfield, VA

Lees K, Pitois S, Scott C, Frid C, Mackinson S (2006) Characterizing regime shifts in the marine environment. Fish Fish 7:104-127

พ Lindegren M, Dakos V, Groger JP, Gårdmark A, Kornilovs G, Otto SA, Möllmann C (2012) Early detection of ecosystem regime shifts: a multiple method evaluation for management application. PLOS ONE 7:e38410

KLitzow MA (2006) Climate regime shifts and community reorganization in the Gulf of Alaska: How do recent shifts compare with 1976/1977? ICES J Mar Sci 63: 1386-1396

*Litzow MA, Hunsicker ME (2016) Early warning signals, nonlinearity, and signs of hysteresis in real ecosystems. Ecosphere 7:e01614

K Litzow MA, Mueter FJ (2014) Assessing the ecological importance of climate regime shifts: an approach from the North Pacific Ocean. Prog Oceanogr 120:110-119

Kitzow MA, Urban D (2009) Fishing through (and up) Alaskan food webs. Can J Fish Aquat Sci 66:201-211

* Litzow MA, Urban JD, Laurel BJ (2008) Increased spatial variance accompanies reorganization of two continental shelf ecosystems. Ecol Appl 18:1331-1337

KLitzow MA, Mueter FJ, Urban JD (2013) Rising catch variability preceded historical fisheries collapses in Alaska. Ecol Appl 23:1475-1487

K Litzow MA, Mueter FJ, Hobday AJ (2014) Reassessing regime shifts in the North Pacific: incremental climate change and commercial fishing are necessary for explaining decadal-scale biological variability. Glob Change Biol 20:38-50

Loring PA (2013) Alternative perspectives on the sustainability of Alaska's commercial fisheries. Conserv Biol 27: $55-63$

Manly BFJ (2006) Randomization, bootstrap and Monte Carlo methods in biology. Chapman and Hall, New York, NY

*Mantua NJ, Hare SR, Zhang Y, Wallace JM, Francis RC (1997) A Pacific interdecadal climate oscillation with impacts on salmon production. Bull Am Meteorol Soc 78: 1069-1079

* McArdle BH, Gaston KJ, Lawton JH (1990) Variation in the size of animal populations: patterns, problems and artefacts. J Anim Ecol 59:439-454

Möllman C, Folke C, Edwards M, Conversi A (2015) Marine regime shifts around the globe: theory, drivers and impacts. Philos Trans R Soc Lond B Biol Sci 370:20130260

Moran PAP (1950) Notes on continuous stochastic phenomena. Biometrika 37:17-23

*Mueter FJ, Litzow MA (2008) Sea ice retreat alters the biogeography of the Bering Sea continental shelf. Ecol Appl 18:309-320 
Mueter FJ, Peterman RM, Pyper BJ (2002) Opposite effects of ocean temperature on survival rates of 120 stocks of Pacific salmon (Oncorhynchus spp.) in northern and southern areas. Can J Fish Aquat Sci 59:456-463

Mueter FJ, Pyper BJ, Peterman RM (2005) Relationships between coastal ocean conditions and survival rates of northeast Pacific salmon at multiple lags. Trans Am Fish Soc 134:105-119

* Orensanz JML, Armstrong J, Armstrong D, Hilborn R (1998) Crustacean resources are vulnerable to serial depletion - the multifaceted decline of crab and shrimp fisheries in the Greater Gulf of Alaska. Rev Fish Biol Fish 8:117-176

Perretti CT, Munch SB (2012) Regime shift indicators fail under noise levels commonly observed in ecological systems. Ecol Appl 22:1772-1779

Petraitis PS, Dudgeon SR (2004) Detection of alternative stable states in marine communities. J Exp Mar Biol Ecol 300:343-371

Petraitis PS, Dudgeon SR (2016) Cusps and butterflies: multiple stable states in marine systems as catastrophes. Mar Freshw Res 67:37-46

Petraitis PS, Hoffman C (2010) Multiple stable states and relationship between thresholds in processes and states. Mar Ecol Prog Ser 413:189-200

Pinheiro JC, Bates DM (2000) Mixed-effects models in S and S-PLUS. Springer, New York, NY

Pyper BJ, Peterman RM (1998) Comparison of methods to account for autocorrelation in correlation analyses of fish data. Can J Fish Aquat Sci 55:2127-2140

R Core Team (2016) R: a language and environment for statistical computing. R Foundation for Statistical Computing, Vienna

Rudnick DL, Davis RE (2003) Red noise and regime shifts. Deep Sea Res I 50:691-699

Samhouri JF, Levin PS, Ainsworth CH (2010) Identifying thresholds for ecosystem-based management. PLOS ONE 5:e8907

Schafer J (1997) Analysis of incomplete multivariate data. Chapman and Hall, New York, NY

Scheffer M, Carpenter S (2003) Catastrophic regime shifts in ecosystems: linking theory to observations. Trends Ecol Evol 18:648-656

Scheffer M, Bascompte J, Brock WA, Brovkin V and others (2009) Early-warning signals for critical transitions. Nature 461:53-59

Scheffer M, Carpenter SR, Lenton TM, Bascompte J and others (2012) Anticipating critical transitions. Science 338: 344-348

Schmidt AE, Botsford LW, Eadie JM, Bradley RW, Di Lorenzo E, Jahncke J (2014) Non-stationary seabird responses reveal shifting ENSO dynamics in the northeast Pacific. Mar Ecol Prog Ser 499:249-258

Schröder A, Persson L, de Roos AM (2005) Direct experimental evidence for alternative stable states: a review. Oikos 110:3-19

Smith TM, Reynolds RW, Peterson TC, Lawrimore J (2008) Improvements to NOAA's historical merged land-ocean surface temperature analysis (1880-2006). J Clim 21: 2283-2296

Spencer PD (2008) Density-independent and density-dependent factors affecting temporal changes in spatial distributions of eastern Bering Sea flatfish. Fish Oceanogr 17: 396-410

Stabeno PJ, Kachel NB, Moore SE, Napp JM, Sigler M, Yamaguchi A, Zerbini AN (2012) Comparison of warm and cold years on the southeastern Bering Sea shelf and some implications for the ecosystem. Deep Sea Res II 6570:31-45

Stachura MM, Essington TE, Mantua NJ, Hollowed AB and others (2014) Linking Northeast Pacific recruitment synchrony to environmental variability. Fish Oceanogr 23: 389-408

Stauffer G (ed) (2004) NOAA protocols for groundfish bottom trawl surveys of the nation's fishery resources. US Department of Commerce, Washington, DC

Stevenson DE, Lauth RR (2012) Latitudinal trends and temporal shifts in the catch composition of bottom trawls conducted on the eastern Bering Sea shelf. Deep Sea Res II 65-70:251-259

The Plan Team for the Groundfish Fisheries of the Bering Sea and Aleutian Islands (2015) Stock assessment and fishery evaluation report for the groundfish resources of the Bering Sea/Aleutian Islands. North Pacific Fisheries Management Council, Anchorage, AK

The Plan Team for the King and Tanner Crab Fisheries of the Bering Sea and Aleutian Islands (2016) Stock assessment and fishery evaluation report for the king and Tanner crab fisheries of the Bering Sea and Aleutian Island regions. North Pacific Fisheries Management Council, Anchorage, AK

Van Buuren S, Oudshoorn CGM (1999) Multivariate imputation by chained equations: MICE v1.0 user's manual. TNO Prevention and Health, Leiden

Veraart AJ, Faassen EJ, Dakos V, van Nes EH, Lürling M, Scheffer M (2012) Recovery rates reflect distance to a tipping point in a living system. Nature 481:357-359

Verhoeven KJF, Simonsen KL, McIntyre LM (2005) Implementing false discovery rate control: increasing your power. Oikos 108:643-647

Wang R, Dearing JA, Langdon PG, Zhang E, Yang X, Dakos V, Scheffer M (2012) Flickering gives early warning signals of a critical transition to a eutrophic lake state. Nature 492:419-422

Wilderbuer TK, Hollowed AB, Ingraham WJ, Spencer PD, Conners ME, Bond NA, Walters GE (2002) Flatfish recruitment response to decadal climatic variability and ocean conditions in the eastern Bering Sea. Prog Oceanogr 55: 235-247

Witherell D, Pautzke C, Fluharty D (2000) An ecosystembased approach for Alaska groundfish fisheries. ICES J Mar Sci 57:771-777

Wood SN (2006) Generalized additive models: an introduction with R. Chapman \& Hall, New York, NY

Wouters N, Dakos V, Edwards M, Serafim MP, Valayer PJ, Cabral HN (2015) Evidencing a regime shift in the North Sea using early-warning signals as indicators of critical transitions. Estuar Coast Shelf Sci 152:65-72

Wyllie-Echeverria T, Wooster WS (1998) Year to-year variations in Bering Sea ice cover and some consequences for fish distributions. Fish Oceanogr 7:159-170

Ye H, Beamish RJ, Glaser SM, Grant SCH and others (2015) Equation-free mechanistic ecosystem forecasting using empirical dynamic modeling. Proc Natl Acad Sci USA 112:E1569-E1576

Yeh SW, Kang YJ, Noh Y, Miller AJ (2011) The North Pacific climate transitions of the winters of 1976/77 and 1988/89. J Clim 24:1170-1183

Zador S (ed) (2015) Ecosystem considerations for 2015. North Pacific Fishery Management Council, Anchorage, AK

Zheng J, Kruse GH (2006) Recruitment variation of eastern Bering Sea crabs: Climate-forcing or top-down effects? Prog Oceanogr 68:184-204

Submitted: April 25, 2016; Accepted: March 30, 2017

Proofs received from author(s): May 10, 2017 